\title{
Lithologic controls on the form of soil mantled hillslopes
}

\author{
Samuel A. Johnstone ${ }^{a}$, George E. Hilley ${ }^{a}$ \\ ${ }^{a}$ Department of Geological Sciences, Stanford University, Stanford, \\ CA 94305 \\ Citation: Johnstone, S.A. and G.E. Hilley (2015), Lithologic control \\ on the form of soil-mantled hillslopes, Geology, V. $43(1), 83-86$, \\ doi:10.1130/G36052.1.
}

\section{Abstract}

Slopes in steady-state soil-mantled landscapes tend to increase downslope in a way that balances local transport capacity with the sediment supplied from progressively larger source areas. Most formulations of sediment transport due to hillslope processes scale transport rate with local slope, which produces convex-up forms that are independent of the properties of the underlying lithologies. In this study, we document soil-mantled hillslopes that show variations in slope that mimic the underlying stratigraphy. We present stratigraphic and soil-thickness measurements, topographic analyses, and numerical models to demonstrate that variations in rock type can impact the forms of these soil mantled hillslopes if hillslope transport rates scale with local slope and soil thickness. This demonstrates that hillslope forms in soil-mantled landscapes can be influenced by the underlying lithology through a coupling between the processes that produce soil from rock and those that transport this soil downslope.

\section{Introduction}

This study investigates how the geologic substrate impacts landscape forms on soil-mantled hillslopes. Gilbert (1877) proposed that when weathering can keep pace with rates of erosion a mantle of soil buffers surface morphologies from the structure of the subsurface geology. Gilbert (1909) then 


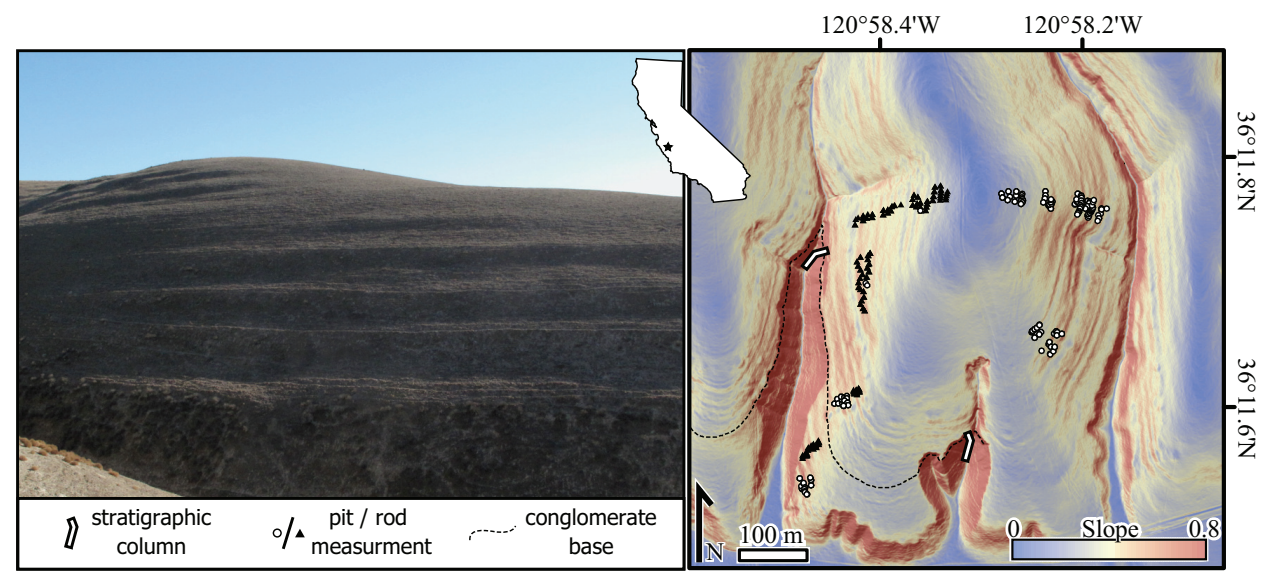

Figure 1: Field photo and shaded slope map illustrate shadow bedding. Map shows locations of stratigraphic sections, locations of thickness measurements, and a prediction for the location of an easily correlated bed in the stratigraphic section. This prediction is the intersection of the topography with a plane fit to points surveyed along the base of that bed and is truncated at a small normal fault in the central arroyo. Slope map produced from 1m ALSM derived DEM collected and processed by NCALM. Additional field photos and stratigraphic column are available in the supplemental material.

reasoned that convex forms characteristic of soil-mantled hillslopes balance the mass of mobile material produced along them with that transported by processes whose rates increase with slope. This model of slope-dependent hillslope transport was later formalized as a hillslope diffusion rule (Geomorphic Transport Law, GTL, sensu Dietrich et al., 2003, Culling, 1960). Previous studies have also proposed that transport rates may depend on slope and soil thickness (Ahnert, 1976; Braun et al., 2001; Anderson, 2002, Roering, 2008; Furbish et al., 2009) and some empirical evidence supports this view (Heimsath et al., 2005; West et al., 2014). Soil thickness may reflect some properties of underlying rocks and rates of erosion (Ahnert, 1976), because rates of soil production are expected and observed to depend on soil thickness and lithology (Heimsath et al. 2005). As a result, variations in underlying rocks may impact soil thickness, and in turn, transport rates. Therefore, changes in transport rates for a given slope that may accompany lithologic contacts should be expressed in the form of soil-mantled hillslopes. If this mechanism is in operation, the proposition of Gilbert (1877) that a soil mantle shields topographic forms from underlying lithologic variations 
needs to be revisited.

Hillslopes in the northern Gabilan Mesa (GM), in the central California Coast Ranges, display the characteristic convex-up morphology predicted by Gilbert (1909) and existing GTLs. However, superimposed on largely convex hillslopes are regular undulations in slope termed 'shadow beds': subhorizontal, soil-mantled features that traverse hillslopes and valleys (Dohrenwend, 1974) (Figure 1). Individual shadow beds seem to correlate with the underlying stratigraphy of the Pancho Rico Formation, suggesting that geologic structure is impacting hillslope forms in this soil-mantled landscape.

We present field surveys of soil thickness, topographic analyses, and stratigraphic measurements that establish the connection between bedrock geology and the morphology of a soil-mantled hillslope. Using numerical simulations of landscapes and modeling field data, we demonstrate that shadow bedding is consistent with the quasi-equilibrium form of hillslopes traversing rocks with varying resistances to disaggregation given a soil-thicknessdependent transport rule. We propose a modified rule for hillslope soil flux that casts flux as the integral of a soil velocity profile that decays exponentially with depth. This velocity profile shows similar dependence on depth as the activity of a number of processes thought to be responsible for soil transport.

\section{Methods}

\subsection{Theory}

Vertically measured soil thickness, $H_{v}[L]$, evolves according to the local input of soil by production, which depends on the surface normal soil thickness, $H[L]$, and the divergence of the flux of soil per unit width, $q_{s}\left[L^{2} t^{-1}\right]$ (e.g., Dietrich et al., 2003):

$$
\frac{d H_{v}}{d t}=\frac{\rho_{b r}}{\rho_{s}} \frac{W_{0}}{\cos (\theta)} e^{-\alpha H}-\nabla \cdot q_{s}
$$

The first term on the right hand side describes the empirically calibrated rate of soil production. $W_{0}\left[L t^{-1}\right]$ is the bedrock lowering rate at zero soil thickness, $\alpha\left[L^{-1}\right]$ is a constant describing the decay in production rate with increasing soil thickness, $\rho_{b r}$ and $\rho_{s}\left[M L^{-3}\right]$ are the densities of bedrock and soil, and $\theta$ is the hillslope angle. Theoretical expectations Ahnert (1976) and empirical evidence (Heimsath et al., 2005) suggest that lithology controls rates of soil production through $W_{0}$, while $\alpha$ is fairly constant across different climates and rock types, with a value of $\sim 2 \mathrm{~m}^{-1}$. Lithology-dependent 
variations in $W_{0}$ require different soil thicknesses to achieve equivalent soil production rates over different lithologies. Adding rock uplift, $U\left[L t^{-1}\right]$, and solving for the evolution of surface elevations, $z[L]$, gives:

$$
\frac{d z}{d t}=U+\left(\frac{\rho_{b r}}{\rho_{s}}-1\right) \frac{W_{0}}{\cos (\theta)} e^{-\alpha H}-\nabla \cdot q_{s}
$$

We assume that downslope soil velocities reach a maximum at the surface and decay exponentially with depth throughout the entirety of the soil column. This is similar to previously developed expressions (Kirkby, 1967; Anderson, 2002, Roering, 2008, Furbish et al., 2009), but ignores the possibility of an inactive region in deep soil columns:

$$
V(h)=V_{0} e^{-h / d_{c}}
$$

The surface normal depth at a point in the soil column is $h[L], d_{c}[L]$ is the scaling depth of the velocity profile, and $V_{0}\left[L t^{-1}\right]$ is the surface velocity. Integrating Equation 3 over $\mathrm{H}$ yields the flux per unit width:

$$
q_{s}=V_{0} d_{c}\left(1-e^{-H / d_{c}}\right)
$$

As $d_{c}$ increases relative to $H$, a greater fraction of the soil column is present in the high velocity portion of the profile and flux becomes increasingly sensitive to variations in thickness. If $d_{c} \gg H$, Equation 4 approaches a plug flow condition, $q_{s}=V_{0} H$. By normalizing the flux in Equation 4 as $q_{s}^{*}=q_{s} /\left(V_{0} H\right)$, such that $q_{s}^{*}=D^{*}\left(1-e^{-1 / D^{*}}\right)$, we capture the sensitivity of flux to soil thickness with the value $D^{*}=d_{c} / H$. As $D^{*}$ increases, variations in soil thickness increasingly impact the flux at a given slope. We incorporate Equation 4 into simulations of landscape evolution by allowing $V_{0}$ to vary as a function of slope and a constant $k\left[L t^{-1}\right]$ :

$$
V_{0}=-k \nabla z
$$

for the case of thickness-dependent linear diffusion or:

$$
V_{0}=\frac{-k \nabla z}{1-\left(\frac{|\nabla z|}{S_{c}}\right)^{2}}
$$

for thickness-dependent nonlinear diffusive transport (Roering, 2008). Here, $S_{c}$ [] is a threshold slope, with values commonly $\sim 1$ (Roering et al. 1999). 


\subsection{Field location and data}

We test this theory with observations from an area of the Gabilan Mesa contained within the Pliocene shallow marine Pancho Rico Formation (Durham and Addicot, 1965). The Pancho Rico Formation comprises beds of mudstone with scattered very fine sand; fine sandstone with scattered coarse sand; and fossiliferous, pebbly conglomerate. Stratigraphy is only exposed at the heads of recently incised arroyos, where two stratigraphic columns were measured (Figure 1).

Soil thickness was measured in soil pits and by driving a rod down to the soil-bedrock contact. We averaged thicknesses that were measured within one LiDAR-DEM pixel $(1 \mathrm{~m})$, which amounts to 115 measurements from soil pits and 112 collected with the rod (Figure 1). The soil-bedrock contact was reliably identified with the rod in some soils, but the rod occasionally penetrated easily disaggregated bedrock. Thus, we base our interpretations and modeling of data only on measurements collected in soil pits. Vertically measured thicknesses were converted to surface-normal measurements using local slope.

To compare the above theory with field data, we assume topographic steady state. Given this, hillslopes should be adjusted to transport the flux received from upslope (Gilbert, 1909), which should scale linearly with the upslope area on the landscape. This allows us to compare data from different hillslope positions according to the drainage area per contour length, $a / b$. We calculate $a$ using the $D_{\text {inf }}$ algorithm (Tarboton, 1997, Perron, 2010), and use the $1 \mathrm{~m}$ pixel dimension as $b$. Slope magnitude is calculated using a second-order, finite-difference kernel in the cardinal directions.

We focus on nonlinear relations between slope and flux, as hillslopes tend to become more planar downslope, with slopes below $\sim 0.5$ (Figures $11 \& 2$ A). A new GTL prediction of flux is presented in each of the three rows of plots shown in Figure 2. These relationships show a nonlinear function of slope (Figure 2 A) (Roering et al. 1999); the product of soil thickness and a nonlinear function of slope (representing transport due to plug flow; Figure 2 C) (Heimsath et al., 2005); and the result of combining Equations

4 and 6 (Figure 2 E) (e.g., Roering, 2008). Plotted against $a / b$ are the components of each GTL that should vary smoothly as a function of $a / b$. Modeled values for these parameters, shown as dashed lines, were computed by least-squares minimization between observed data and a prediction based on the relevant GTL and the steady state assumption (e.g., Roering et al., 1999 , justification in supporting material). For GTLs that depend on soil thickness, we use the mean soil thickness from our observations to develop 
this single prediction. In the right column of plots we test if deviations from the modelled predictions correlate with soil thickness.

\subsection{Simulating landscapes}

To illustrate the variable role lithology may play in shaping landscapes as a function of $D^{*}$ we numerically integrate Equations 1 and 2 through the application of Equations 4 and 5 from a flat initial topography in 1D. The model domain was subjected to uniform uplift except at the boundaries, whose elevations were held fixed. To approximate a situation such as that in the GM, we assume that lithology controls $W_{0}$ and let this vary with the amount of exhumation that has occurred at a point. Here, modeled topography is incising through laterally continuous oscillations between 2.5 $m$ thick "recessive" and "resistant" beds; we specify these as having values of $W_{0} 50 \%$ greater or less than a mean value, respectively. The cyclic values of $W_{0}$ are advected upward by $U$, causing the model to evolve to a state in which relief oscillates around a mean value. To ensure initial topographic conditions were eliminated, we ran the model for $4 \times 10^{6}$ model years, a total uplift of $>10 \mathrm{x}$ the total basin relief.

\section{Results}

\subsection{Soil thickness and topography}

For a given $a / b$, slopes are higher above thin soils (Figure 2 A \& B). This is seen as a negative bias in the residuals as a function of soil thickness (Figure 2 B). Bias increases for the case that a soil thickness, slope product relates soil thickness to transport rate at a given slope (Figure 2 C \& D). The velocity-profile-based prediction does not eliminate the noise present in the data (Figure $2 \mathrm{E}$ ). However, with a $d_{c}$ of $12 \mathrm{~cm}$, the segregation of points at a particular value of $a / b$ based on thickness (e.g., Figure 2 A \& B) is no longer present. This is reflected in the residuals, which are generally centered near zero for all but the thinnest soils (Figure $2 \mathrm{~F}$ ).

\subsection{Modeling}

In Figure $3 \mathrm{~A}$, we plot $q^{*}$ as a function of $D^{*}$ to reference each of the simulation results shown. Variations in $H$ arise from the variations in $W_{0}$ in these simulations. As a result there are steady-state values of $D^{*}$ for resistant (low $D^{*}$ ) and recessive (high $D^{*}$ ) layers; bars in Figure 3 B show 


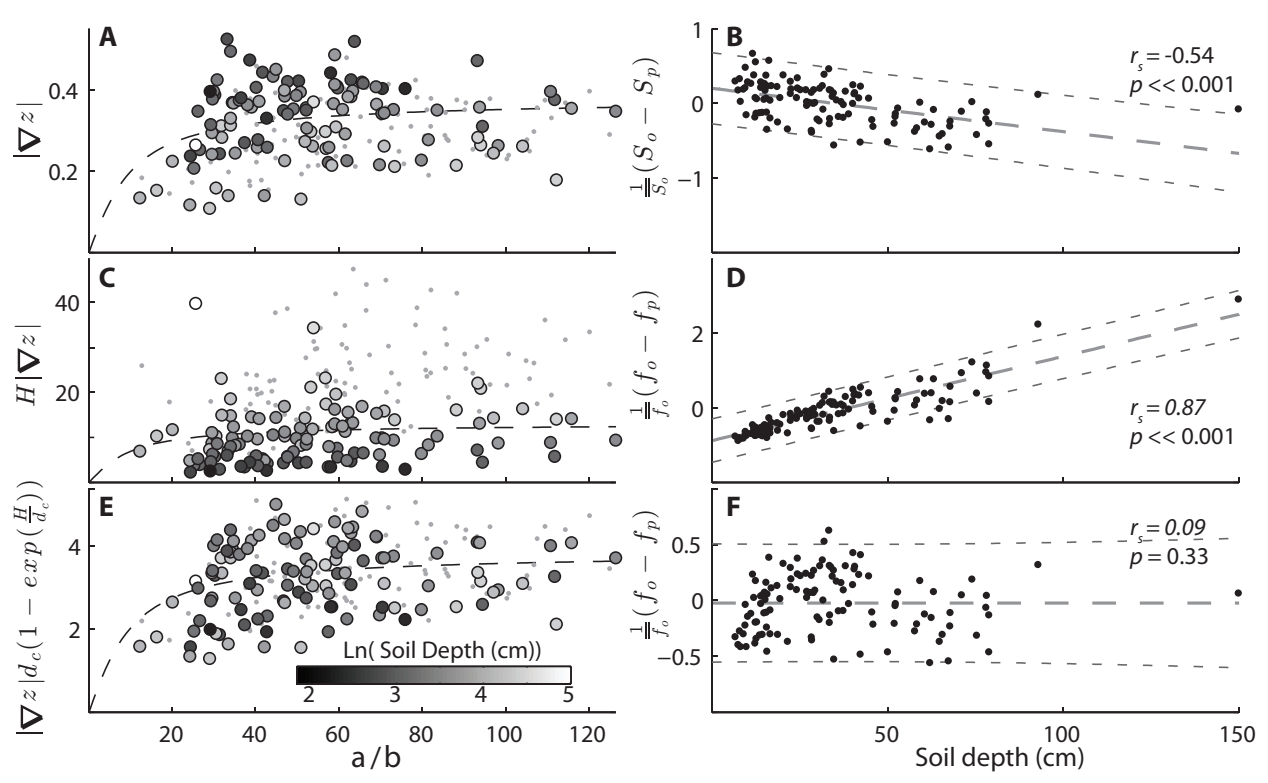

Figure 2: GTL predictions plotted against a/b (A,C,E) and the residuals between models fits based on these predictions and data (B,D,F). Residuals are reported as the difference between observed and predicted slopes, $S_{o}$ and $S_{p}$, or observed and predicted functions of slopes and thickness, $f_{o}$ and $f_{p}$, and normalized to the mean observed value. Large circles are color-coded by soil thickness, small dots are points measured with the rod and were not used in any analysis. Dashed lines in B, $\mathrm{D}$, and $\mathrm{F}$ show a linear regression with $95 \%$ confidence intervals. Spearman's rank correlation coefficient, $r_{s}$, and a p-value estimate for the no-correlation hypothesis are also reported in each plot. 
the range of these values within each simulation. We scale $k$ in Equation 5 so that flux remains relatively constant for a given slope and soil thickness, which reduces fluctuations in relief as $d_{c}$ varies.

Soil thickness varies in all the simulations, but small values of $D^{*}$ (Figure 3 i) decouple soil production and transport in a way that prevents variations in soil thickness (and hence lithology) from being expressed in the modeled topography. For larger values of $D^{*}$, balancing upslope sediment supply requires that $V_{0}$ (and thus slope) must change to compensate the changes in $H$ that arise at lithologic boundaries. $D^{*}$ values of $\sim 1$ (Figure 3 ii) produce weak correspondence between slope and soil thickness, an effect that becomes progressively more pronounced as $D^{*}$ increases (Figure 3 iii \& iv).

\section{Discussion}

Beds in the Pancho Rico stratigraphy can be traced from exposures in arroyos to laterally continuous undulations in slope on soil mantled hillslopes (Figure 1). Soils tend to be thinner in steep portions of these shadow beds than in low slope sections (Figure 2 A \& B). A linear relationship between soil thickness and transport overestimates transport through thick soils, suggesting transport does not occur at equivalent rates throughout the soil column (Figure 2 C \& D). A prediction of flux based on Equation 3 accounts for variations in transport with depth in the soil column, and produces a balanced estimate of sediment flux along the length of the hillslope when $d_{c}$ is $12 \mathrm{~cm}$ (Figure 2 E). This prediction results in some bias in the residuals of the thinnest soils toward negative values (Figure $2 \mathrm{~F}$ ), perhaps related to an underestimation of high slopes on gridded data or the fact that the proposed velocity profile is an oversimplification (Kirkby, 1967; Lewis, 1976). What remains to be demonstrated is that $W_{0}$ varies with the lithologies present and that the proposed velocity profile (Equation 3 ) matches velocity profiles from the GM.

Numerical modeling (Figure 3 ii-iv) demonstrates that landscape forms influenced by subsurface lithology can occur if rates of soil transport, $q_{s}$, depend on soil thickness and slope (Equation 4- 6) and if different lithologies require different soil thicknesses to achieve equivalent soil production rates (Ahnert, 1976; Heimsath et al., 2005). Shadow beds form in simulations of hillslopes crossing lithologic contacts, represented with values of $W_{0}$, when soil is transported with the proposed velocity profile as long as $H$ is small relative to $d_{c}$ (Figure 3 iii and iv). 
Soil transport is commonly related to the disturbance of soils yielding a net-downslope flux (Davis, 1892, Culling, 1960; Roering et al., 1999). The velocity profile we model could alternatively reflect a decrease in the frequency of soil-disturbing events with depth. We use the term 'activity' to refer to some measure of the soil disturbance accomplished by a range of processes. Ground-squirrel burrows and drying cracks in soils suggest that burrowing and shrink-swell processes are two important agents in soil disturbance in the GM. Data on the depth dependence of these and other soil disturbing processes suggest that their activity commonly declines with depth (Figure 3 A). This suggests that the upper portions of the soil consist of rapidly mobilized material, while deeper portions may be disturbed less frequently. In thin soils the high-activity zone may include the entire mobile layer (e.g., high $D^{*}$ ), generating a tight coupling between soil production and landscape form. In thick soils, transport may be decoupled from deep portions of the soil column and landscape forms may be less sensitive to soil production processes.

How common is lithologic control on hillslope form? Our simulations of 1D landscapes evolving by linear, depth-dependent transport indicate that the sensitivity of soil-mantled landscapes to thickness occurs when $q_{s}^{*}>\sim$ $0.5-0.7$ (Figure 3B), which occurs when $D^{*}>\sim 1-\sim 2$. Given a hillslope where soil thickness has adjusted so that soil production rates match rock uplift rates, $D^{*}$ can be calculated as:

$$
D^{*}=\frac{d_{c}}{H}=\frac{-\alpha d_{c}}{\ln \left(\frac{U \cos \theta}{W_{0}}\right)}
$$

In the case that $\alpha^{-1}$ and $d_{c}$ are similar and $\theta$ is small, the equilibrium $D^{*}$ only depends on $U$ and $W_{0}$. In this situation, values of $D^{*}$ will exceed $\sim 1$, and fluxes will be sensitive to soil thickness, when the ratio of $U$ to $W_{0}$ is greater than $\sim e^{-1}(\sim 0.4)$. For a value of $W_{0}$ around $\sim 0.1 \mathrm{~mm} / \mathrm{yr}($ Dietrich et al., 2003), and assuming $W_{0}$ and $U$ are uncorrelated, soil mantled landscapes where uplift (or mean erosion rates) are greater than $0.04 \mathrm{~mm} / \mathrm{yr}$ are likely to be sensitive to variations in soil thickness (and therefore lithology). This suggests that a broad range of soil-mantled hillslopes may encode some signature of the underlying rock type. However, the dominance of nonlinear hillslope transport (Roering et al., 1999) in steep terrains may allow small changes in slope to compensate for potentially large variations in $W_{0}$. Ultimately, nonlinear hillslope transport may limit features such as shadow beds to landscapes with large variations in $W_{0}$ and in which base-level lowering is rapid enough to produce thin soils, but slow enough (and with hillslopes 


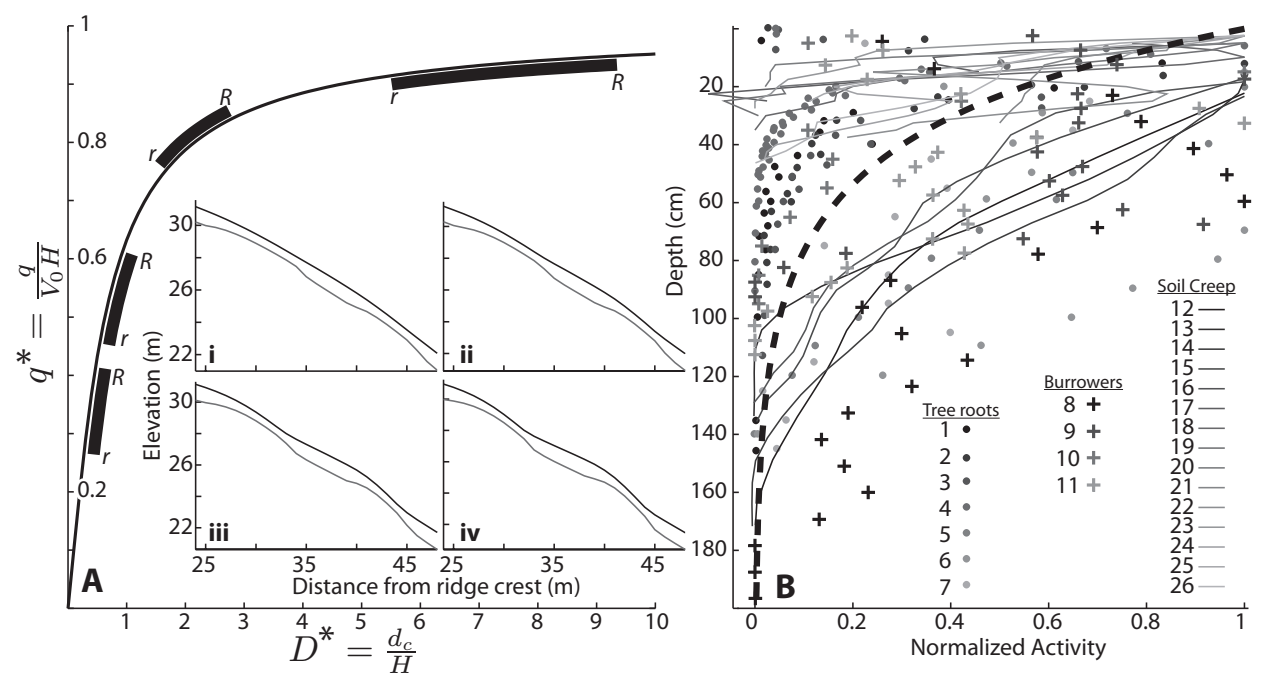

Figure 3: A) Dimensionless flux as a function of $D^{*}$. Inset plots i-iv show hillslope simulations with flux calculated by Equation 4 and 5 , black line is the land surface, gray line is the soil bedrock contact. Black bars show the $D^{*}$ values for the range of thicknesses that arise over resistant $(R)$ and recessive $(r)$ layers. B) Variability in the activity of agents thought responsible for soil disturbance with depth. All values are normalized to the maximum reported value of each. Normalizing values and type of measurements are given in the supplement1. Heavy dashed line is a velocity profile (Equation 3) with a $d_{c}$ of $33 \mathrm{~cm}$. Data from: 1-4 Danjon et al. (1999); 5-6 Danjon et al. (2008); Roering et al. (2010); 8 Grinnell and Dixon (1918); 9 Kolb (1985); 10 Miller (1957); 11 Yensen et al. (1991); 12-16 Fleming and Johnson (1975); 17-20 Kirkby (1967); 21-25 Lewis (1976); 26 Moeyersons (1988).

short enough) to maintain slopes well below their critical values.

\section{Acknowledgements}

We thank K.D. Chadwick, S. Moon, A. Sanquini, G. Seixas, and E. Shelef for invaluable discussions and feedback on earlier versions of this manuscript, and R. Klier, J. Perkins, and G. Seixas for their efforts in the field. Reviews/comments by A. Heimsath, J. Roering, an anonymous reviewer, and J. Spotila greatly improved this manuscript. The generosity of L. Homen allowed this work to proceed. Support for SAJ was provided by NSF grant EAR-TECT-105581. Fieldwork was funded through Stanford McGee/Levorsen and GSA Graduate Research grants to SAJ. Acquisition and processing of 
ALSM LiDAR data provided by the NCALM seed grant program.

\section{References}

Ahnert, F. (1976). Brief description of a comprehensive three-dimensional process-response model of landform development. Zeitschrift für Geomorphologie Supplemental, 25:29-49.

Anderson, R. S. (2002). Modeling the tor-dotted crests, bedrock edges, and parabolic profiles of high alpine surfaces of the Wind River Range, Wyoming. Geomorphology, 46(1-2):35-58.

Braun, J., Heimsath, A. M., and Chappell, J. (2001). Sediment transport mechanisms on soil-mantled hillslopes. Geology, 29(8):683.

Culling, W. (1960). Analytical Theory of Erosion. The Journal of Geology, 68(3):336-344.

Culling, W. (1963). Soil Creep and the Development of Hillside Slopes. The Journal of Geology, 71(2):127-161.

Danjon, F., Barker, D. H., Drexhage, M., and Stokes, A. (2008). Using threedimensional plant root architecture in models of shallow-slope stability. Annals of botany, 101(8):1281-93.

Danjon, F., Sinoquet, H., Godin, C., Colin, F., and Drexhage, M. (1999). Characterisation of structural tree root architecture using 3D digitising and AMAPmod software. Plant and Soil, 211:241-258.

Davis, W. M. (1892). Convex profile of bad-land divides. Science, 20(508):245-246.

Dietrich, W. E., Bellugi, D. G., Sklar, L. S., Stock, J. D., Heimsath, A. M., and Roering, J. J. (2003). Geomorphic transport laws for predicting landscape form and dynamics. AGU, Washington, D.C.

Dohrenwend, J. C. (1974). Geology of the central salinas valley and adjacent uplands, Monterey County, California. Ph.d. thesis, Stanford University.

Durham, D. L. and Addicot, W. O. (1965). Pancho Rico Formation Salinas Valley, California. U.S. Geological Survey Professional Paper, 524A:22. 
Fleming, R. W. and Johnson, A. M. (1975). Rates of seasonal creep of silty clay soil. Quarterly Journal of Engineering Geology and Hydrogeology, $8(1): 1-29$.

Furbish, D. J., Haff, P. K., Dietrich, W. E., and Heimsath, A. M. (2009). Statistical description of slope-dependent soil transport and the diffusionlike coefficient. Journal of Geophysical Research, 114:F00A05.

Gilbert, G. (1877). Report on the Geology of the Henry Mountains. US Geographical and Geological Survey, Washington, D.C.

Gilbert, G. (1909). The Convexity of Hilltops. The Journal of Geology, $17(4): 344-350$.

Grinnell, J. and Dixon, J. (1918). Natural history of the ground squirrels of California. Monthly Bulletin of the California State Commission on Horticulture, 7:597-708.

Heimsath, A. M., Furbish, D. J., and Dietrich, W. E. (2005). The illusion of diffusion: Field evidence for depth-dependent sediment transport. Geology, 33(12):949.

Kirkby, M. (1967). Measurement and Theory of Soil Creep. The Journal of Geology, 75(4):359-378.

Kolb, H. H. (1985). The burrow structure of the European rabbit (Oryctolagus cuniculus L.). Journal of Zoology, 206:253-262.

Lewis, L. (1976). Soil movement in the tropics - a general model. Zeitschrift für Geomorphologie Supplemental1, 25:132-144.

Miller, M. A. (1957). Burrows of the Sacramento Valley pocket gopher in flood-irrigated alfafa fields. Hilgardia, 26:431-452.

Moeyersons, J. (1988). The complex nature of creep movements on steeply sloping ground in Southern Rwanda. Earth Surface Processes and Landforms, 13:511-524.

Perron, J. T. (2010). TopoTools for Matlab (Version 1.0).

Roering, J. J. (2008). How well can hillslope evolution models "explain" topography? Simulating soil transport and production with high-resolution topographic data. Geological Society of America Bulletin, 120(9-10):12481262 . 
Roering, J. J., Kirchner, J. W., and Dietrich, W. E. (1999). Evidence for nonlinear, diffusive sediment transport on hillslopes and implications for landscape morphology. Water Resources Research, 35(3):853-870.

Roering, J. J., Marshall, J., Booth, A. M., Mort, M., and Jin, Q. (2010). Evidence for biotic controls on topography and soil production. Earth and Planetary Science Letters, 298(1-2):183-190.

Tarboton, D. G. (1997). A new method for the determination of flow directions and upslope areas in grid digital elevation models. Water Resources Research, 33(2):309-319.

West, N., Kirby, E., Bierman, P., and Clarke, B. a. (2014). Aspect-dependent variations in regolith creep revealed by meteoric 10Be. Geology, 42(6):507510 .

Yensen, E., Luscher, M. P., and Boyden, S. (1991). Structure of Burrows Used by the ldaho Ground Squirrel, Spermophilus brunneus. Northwest Science, 65:93-99. 


\section{Supporting material}

\subsection{Assumption of steady state soil flux}

For a 1-dimensional, non-linear thickness independent transport rule, topographic steady state predicts that:

$$
q=k \frac{S}{\left.\left(1-\left(S / S_{c}\right)^{2}\right)\right)}=U \frac{\rho_{b r}}{\rho_{s}} x
$$

Where $S$ [ ] is the topographic slope, $x[\mathrm{~L}]$ is the distance from the divide, and all other parameters are defined in the main text. Similar expressions can be derived to calculate slope for linear and thickness-dependent transport rules as well. Non-linear equations (e.g., Equation 6 and 8) can be solved iteratively for $S$ to predict how slope varies as a function of $x$, while equilibrium slopes can be calculated directly for linear equations (e.g., Equation 5). To develop a continuous prediction for slope along our hillslopes (as shown in Figure 3), we minimize the sum of the squared errors between the equilibrium assumption (defined above) and topographic data. In two dimensions we use the drainage area per contour length, $a / b$, in place of $x$ (Roering et al., 1999), where the contour length is specified as the grid cell width $(1 \mathrm{~m})$. This accounts for convergence and divergence of flux due to planform curvature. Drainage area was calculated using the $D_{\text {inf }}$ algorithm (Tarboton, 1997; Perron, 2010).

Many of the hilltops in the Gabilan Mesa are characterized by a low-relief surface defined by the Paso Robles formation, suggesting that, on the whole, this landscape is not at topographic equilibrium and that this approach may not be valid. To assess the quality of our assumption of steady state, we present results of simulations of one dimensional evolving topography. With these we demonstrate that while the hillslope studied is not likely to be in steady state, the current slopes are still likely to vary with distance in a similar manner to those predicted by the steady-state approximation.

To compare our simulated landscapes to the real landscape of the Gabilan Mesa, we define a dimensionless number that compares the minimum amount of exhumation (' $\min |E|$ ' in Figure 5) that has occurred on a hillslope to the current relief on the hillslope. For a simulation evolving due to fixed base levels and uplift of an initially flat topography this is expressed as:

$$
E^{*}=\frac{U t}{Z_{\text {crest }}}
$$


Where $t[t]$ is the total time that has elapsed in the simulation such that $U\left[L t^{-1}\right]$ is the rate of uplift or base level lowering and $Z_{\text {crest }}[L]$ is the elevation at the crest of the hill. Due to the preservation of the Paso Robles surface in the Gabilan Mesa we can also define an equivalent quantity for our field site:

$$
E^{*}=\frac{R_{\text {surf }}}{R_{h s}}
$$

Where $R[L]$ is the relief and the subscripts surf and $h s$ denote the relict land surface and hillslope, respectively. We define relief as the difference in elevation between the base of hillslopes and the Paso Robles surface and hill crest, respectively. The development of some subtle topography on this surface indicates that even where best preserved this surface has likely been lowered slightly. The crest of the hillslope studied here is approximately 20 - $30 \mathrm{~m}$ below this low-relief surface and has $\sim 100 \mathrm{~m}$ of relief, suggesting it has an $E^{*}$ value of 1.2 .

In Figure 5 we present comparisons between the equilibrium slope and actual slope for values of $E^{*}$ of $1.1,1.2,1.5$, and $\sim 4$ for linear (Figure 5 B) and non-linear (Figure 5 C) simulations of evolving hillslope profiles. Equilibrium slopes are plotted on the y-axis, slopes at different stages of $E^{*}$ are shown on the $\mathrm{x}$-axis of each plot, and points are color coded for different $E^{*}$ values. Dashed lines are contours of current slopes being $100 \%, 80 \%$, and $60 \%$ of equilibrium slopes.

In the range of $E^{*}$ values similar to those of the study area, slopes are only $60-80 \%$ of steady state slopes. However, they are relatively consistent about this value (particularly in the non-linear case) along the length of the hillslope. That is, when using slope to solve for flux in these transient settings, the degree of misestimation of flux is similar along the length of the hillslope. In Figure 2, we are not trying to calibrate erosion rates or fluxes specifically; rather we are simply trying to use the current topography to model slopes as a continuous function of topographic position. For this reason we feel justified that the modeled slopes shown in Figure 2 provide a reasonable, continuous prediction for slopes along the hillslope from which we can measure residuals. Additionally, because the fluxes calculated from these modeled fits are not likely to be true steady-state fluxes, the parameters calibrated by minimizing the error between actual and predicted slopes are irrelevant and therefore not reported. 


\subsection{Colluvial hollows}

An interesting feature of shadow bedding is that it appears to be crosscut by soil accumulations in colluvial hollows. That is, the oscillations in slope that define shadow bedding are truncated in areas of convergent hillslope topography. Figures 1 and $7 \mathrm{~A}$ and $\mathrm{B}$ highlight an example of a colluvial hollow cross cutting shadow bedding in a photograph and slope map of the same hillslope. Beneath the yellow star (and on the north end of Figure 7 B) is an area of planform concavity on an otherwise convex to planar hillslope. Shadow beds can be traced continuously along this hillslope until encountering this concavity, where they are terminated and reappear again on the opposite side at an equivalent topographic position.

In the main text we argue that shadow bedding arises such that variations in slope balance variations in soil thickness to yield a uniform flux given a thickness-dependent soil flux rule. An end-member alternative to this equilibrium hypothesis is a purely transient one. Rather than reflecting thickness-dependent transport, perhaps shadow bedding is a remnant feature that has yet to equilibrate to the expected smooth, convex topographic forms characteristic of soil mantled hillslopes. Specifically, hillslopes in the Wildhorse Valley may still be responding to some episode in the past that thinned or stripped soils and produced a stepped bedrock or thinly soilveiled topography. We argue here that the observation of soil accumulations in colluvial hollows that crosscut shadow bedding precludes this hypothesis. Specifically, that diffusion-like behavior of purely slope dependent soil transport (Culling, 1960, 1963) will act to smooth high-frequency topography before accumulating soil preferentially in colluvial hollows. To test this we present results of simulations from a two-dimensional hillslope model identical to the one presented in the main text (Figure 7 C).

We evolve these simulations from an initially stepped topography for $\sim 15$ ka model years given a thickness-independent transport rule (Culling, 1960, 1963) and the integrated soil velocity profile presented in Equations 4 and 5 of the main text. The initially stepped topography consists of slopes that oscillate between different lithologies. A uniform, thin mantle of soil $(5 \mathrm{~cm})$ is applied to the model, so that fluxes are non-zero at the start of the simulation. We represent different lithologies as having values of $W_{0}$ which vary $50 \%$ about a mean value. We introduce plan form curvature into the topography to represent colluvial hollows. The base of the model $(\mathrm{y}$-Distance $=0)$ is fixed at 0 elevation; all other boundaries are periodic. We do not uplift the model or continually lower base level, as this would ultimately have the effect of removing the planform curvature - which is the 
feature we are fundamentally interested in observing.

In the thickness-independent model (Figure 7 i-iii), the initially stepped topography quickly begins to diffuse, and by 10 ka remnants of the initially stepped topography are present, but strongly subdued. By 15 ka there is no record of the initially stepped topography in the hollows or on the convex hillslopes. By contrast, in the thickness-dependent model (Figure 7 iv - vi), the initially stepped topography does not diffuse as quickly (as soil thicknesses and therefore fluxes are low), preserving the initially stepped topography in both the simulated hollows and convex portions of hillslopes. However by $15 \mathrm{ka}$, accumulations of soil in hollows has resulted in differential preservation of the formerly stepped topography. While subdued steps are still present on the convex portions of the slope, they are absent from the hollows. This occurs because accumulations of soil thickness push the hollows to low values of $D^{*}$, causing flux to be relatively insensitive to fluctuations in depth (Figure 3 B \& i). While no results are shown here, when performing identical simulations with a plug-flow flux rule (e.g., $q=k H \nabla z$ ), the lithologic undulations are equally preserved in both the convex and concave portions of the landscape. Unlike in the integrated velocity profile (Figures 7 iv-vi), with the plug-flow rule variations in the thickness of soils require variations in slope to balance fluxes, regardless of soil thickness.

These simulations support our hypothesis of thickness-dependent soil flux, and in particular a transport rule that accounts for the decay in downslope soil velocities with depth in the soil column. Even in the case that hillslopes are equilibrating from a past event that produced stepped, bedrock topography, the observation that colluvial hollows cross cut shadow bedding requires a thickness-dependent transport rule.

\section{Figures and tables}




\begin{tabular}{|c|c|c|c|c|c|}
\hline \multirow{2}{*}{$\begin{array}{l}\text { ID } \\
\text { Trees }\end{array}$} & \multirow[t]{2}{*}{ Publication } & & & \multicolumn{2}{|l|}{$\begin{array}{l}\text { Maximum } \\
\text { Value }\end{array}$} \\
\hline & & $\begin{array}{l}\text { Measurement } \\
\text { ID }\end{array}$ & Species & & \\
\hline 2 & & Oak 2 & $\begin{array}{l}\text { Sessile oak, Quercus } \\
\text { petraea }\end{array}$ & $6.59 \mathrm{E}+02$ & $\mathrm{~cm}^{3}$ \\
\hline 4 & & Pine (30 trees) & $\begin{array}{l}\text { Mean of } 30 x \text { Maritime } \\
\text { pine, Pinus pinaster }\end{array}$ & $1.91 \mathrm{E}+02$ & $\mathrm{~cm}^{3}$ \\
\hline 5 & Danjon et al., 2008 & Tree D & $\begin{array}{l}\text { White oak, Quercus } \\
\text { alba }\end{array}$ & $1.11 \mathrm{E}+03$ & $\mathrm{~cm}^{2}$ \\
\hline \multicolumn{2}{|c|}{ Burrowers } & $\begin{array}{l}\text { Measurement } \\
\text { type }\end{array}$ & & & \\
\hline 8 & $\begin{array}{l}\text { Grinnell and Dixon, } \\
1918\end{array}$ & $\begin{array}{l}\text { Burrow Area (from } \\
3 \text { sketches) }\end{array}$ & $\begin{array}{l}\text { Ground squirrel, Oto- } \\
\text { spermophilus beecheyi }\end{array}$ & $6.21 \mathrm{E}+03$ & $\mathrm{~cm}^{2}$ \\
\hline 9 & Kolb, 1984 & $\begin{array}{l}\text { Burrow Area (from } \\
\text { sketch) }\end{array}$ & $\begin{array}{l}\text { European rabbit, } \\
\text { Oryctolagus cuniculus }\end{array}$ & $7.23 \mathrm{E}+02$ & $\mathrm{~cm}^{2}$ \\
\hline 10 & Miller, 1957 & Burrow Volume & $\begin{array}{l}\text { Pocket gopher, Tho- } \\
\text { momys umbrinus }\end{array}$ & $5.23 \mathrm{E}+05$ & $\mathrm{~cm}^{3}$ \\
\hline 11 & Yensen et al., 1991 & $\begin{array}{l}\text { Burrow Area (from } \\
\text { sketch) }\end{array}$ & $\begin{array}{l}\text { Ground squirrel, Sper- } \\
\text { mophilus brunneus }\end{array}$ & $9.12 \mathrm{E}+02$ & $\mathrm{~cm}^{2}$ \\
\hline 16 & & $\mathrm{~S} 20$ & $1.14 \mathrm{yrs}$ & $1.02 \mathrm{E}+00$ & $\mathrm{~cm}$ \\
\hline 17 & Kirkby, 1967 & Bluff & $1-2$ yrs & $1.33 \mathrm{E}-01$ & $\mathrm{~cm} \mathrm{yr}^{-1}$ \\
\hline 18 & & Peat & $1-2$ yrs & $1.10 \mathrm{E}-01$ & $\mathrm{~cm} \mathrm{yr}^{-1}$ \\
\hline 19 & & Rock & $1-2$ yrs & $3.13 \mathrm{E}-01$ & $\mathrm{~cm} \mathrm{yr}^{-1}$ \\
\hline 20 & & Till & $1-2$ yrs & $1.54 \mathrm{E}-01$ & ${\mathrm{~cm} \mathrm{yr}^{-1}}^{-1}$ \\
\hline 21 & Lewis, 1976 & Marimonte & 5.4 yrs & $2.50 \mathrm{E}+01$ & $\mathrm{~cm}$ \\
\hline 22 & & Infiernillo & $4.4 \mathrm{yrs}$ & $1.70 \mathrm{E}+01$ & $\mathrm{~cm}$ \\
\hline 23 & & Coama & 5.4 yrs & $2.54 \mathrm{E}+01$ & $\mathrm{~cm}$ \\
\hline 24 & & LaPaguera & $4.4 \mathrm{yrs}$ & $1.50 \mathrm{E}+01$ & $\mathrm{~cm}$ \\
\hline 25 & & Piedra & $4.4 \mathrm{yrs}$ & $1.34 \mathrm{E}+01$ & $\mathrm{~cm}$ \\
\hline 26 & Moeyersons, 1987 & & 4 yrs & $1.50 \mathrm{E}+00$ & $\mathrm{~cm}$ \\
\hline
\end{tabular}

Table 1: Summary of data compiled and shown in Figure 3 B. ID corresponds to the legend shown in Figure 3 B. Measurement ID refers to the sample or location number in the publication. Maximum value gives the units and value used to normalize each data set. When appropriate, we specify either the species studied or the duration of the measurement interval over which creep rates or distances were measured. 

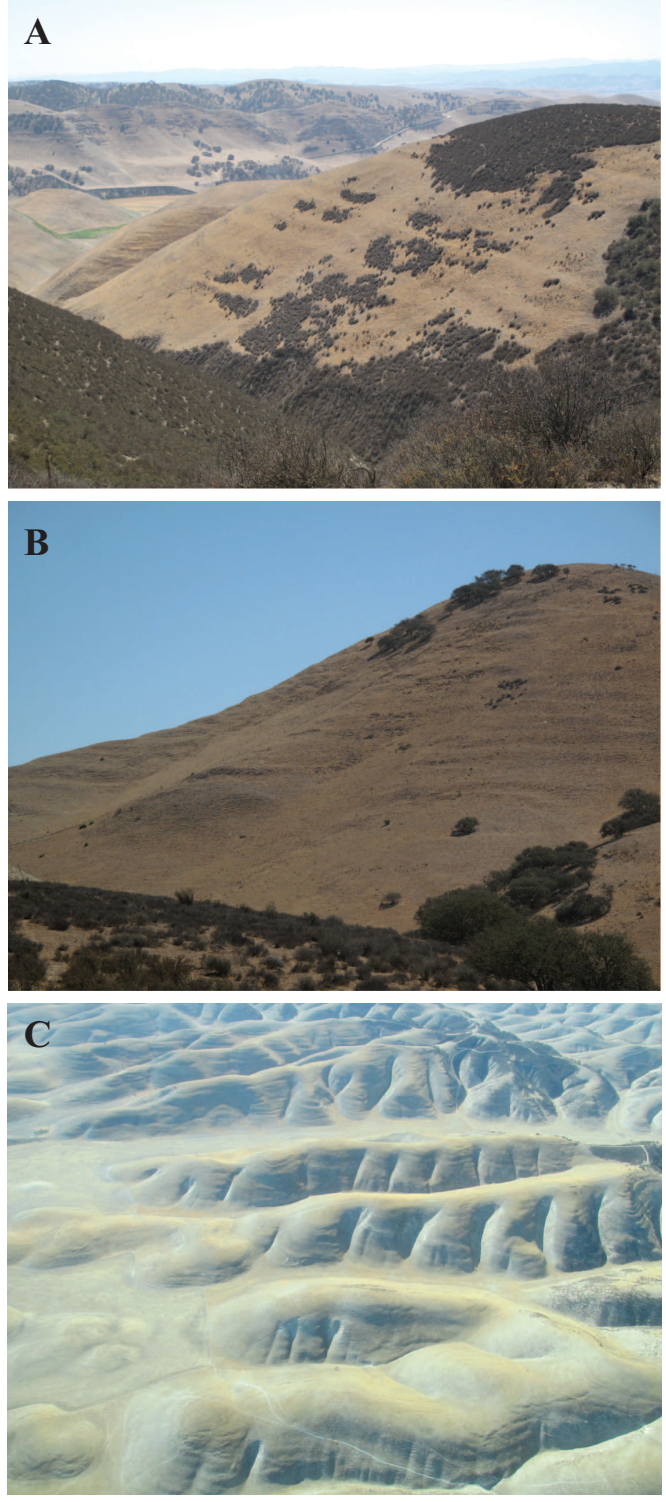

Figure 4: Additional field photos documenting shadow bedding from the Northern Gabilan Mesa. A) Shadow bedded hillslope with cross cutting colluvial hollows south of Topo Valley Road. B) Shadow bedding is seen on hillslopes in the foreground and background of this South Facing Photo. Pancho Rico Creek forms the valley in the midground of the photo. In the foreground, shadow bedding is partially highlighted by variations in vegetation. C) Aerial photograph highlighting that shadow bedding can be traced for long distances along hillslopes and across valleys. Photo courtesy of Juan C. Fernandez Diaz 

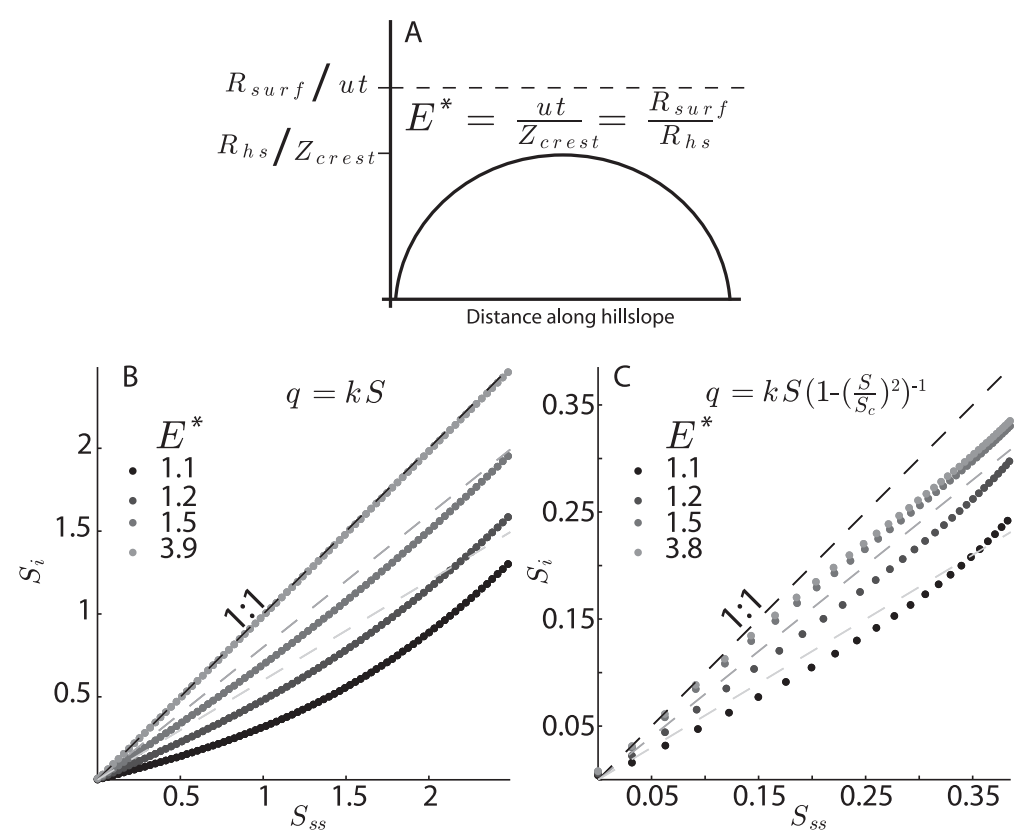

Figure 5: Transient slope evolution of linear and non-linear hillslopes. A) Depiction of terms used to compare real and modeled landscapes. Solid line depicts hillslope, dashed line shows the total uplift that has accrued or, alternatively, an incised landscape surface. $E^{*}$ depends on the degree to which hillslopes have evolved beyond their initial condition and may be defined in the field utilizing an incised but relatively continuous geomorphic surface (the "mesa" of the Gabilan Mesa). The two presented equations for $E^{*}$ may be used to calculate this value in different circumstances. In the field, direct measurements of the hillslope relief, $R_{h s}$, and the incised surface relief, $R_{\text {surf }}$, can be made. In simulations, the equivalent quantities are the elevation of the hillslope crest, $Z_{\text {crest }}$, and the product of the uplift rate, $u$, and the model time, $t$. Relief is defined relative to the elevation at the base of the hillslope. The crest of the hillslope studied here is approximately $20-30$ $\mathrm{m}$ below the low-relief mesa surface and has $100 \mathrm{~m}$ of relief, suggesting it has an $E^{*}$ value of $\sim 1.2$. B and C) Plots of the steady-state slope, $S_{s s}$, plotted against the slope at a specified simulation time, $S_{i}$, for different values of $E^{*}$. In $\mathrm{B}$ this is shown for a system evolving according to a linear transport rule, while in $\mathrm{C}$ the simulation was governed by a non-linear transport rule, as indicated by the titles of each plot. Dashed lines are contours of current slopes being $100 \%, 80 \%$ and $60 \%$ of equilibrium slopes. 


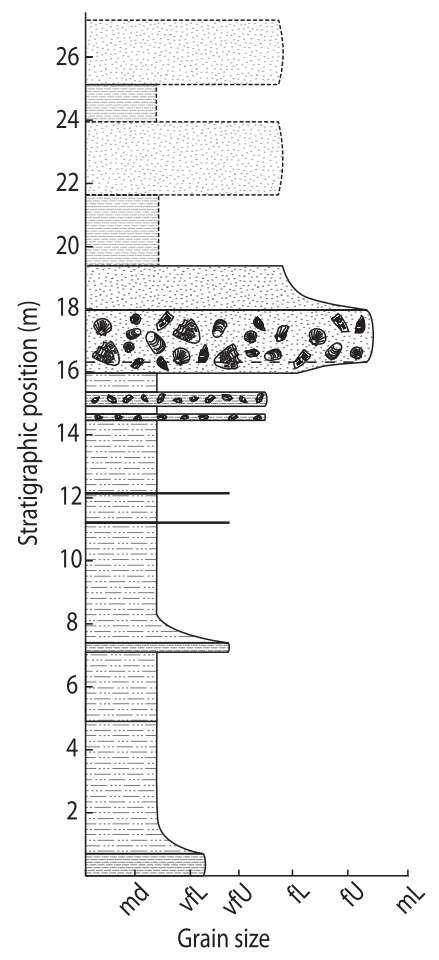

Figure 6: Composite stratigraphic section from two sections measured at nearly equivalent stratigraphic positions in the Pancho Rico Formation. Sections were correlated based on the resistant, bioclastic conglomerate unit 16 $\mathrm{m}$ from the base of the displayed section. The expected location of this conglomerate in the landscape is shown in Figure 1, and was computed by least-squares fitting of a plane to the surveyed basal contact of this bed. Dotted outlines of stratigraphy indicate beds that could not be accessed directly in one section and were partly soil mantled in the other. Measurements of thickness in these top beds were made from photographs, theodolite, GPS surveys and grain-size profiles were partly inferred from weathering profiles and based on limited outcrop access. Grain sizes are reported for the matrix, scale is labelled as mud (md), very-fine lower and upper sand (vfL and $\mathrm{vfU}$ ), fine lower and fine upper sand (fL and $\mathrm{fU}$ ), and medium lower sand $(\mathrm{mL})$. Shell and rare pebble clasts are seen in beds near the middle of the section. In the two thin beds between 14 and 16 meters, long axis of clasts are typically $1-2 \mathrm{~cm}$ in diameter. In the thicker bed, fossil clasts are typically $\sim 5-10 \mathrm{~cm}$ and in some cases even larger. 

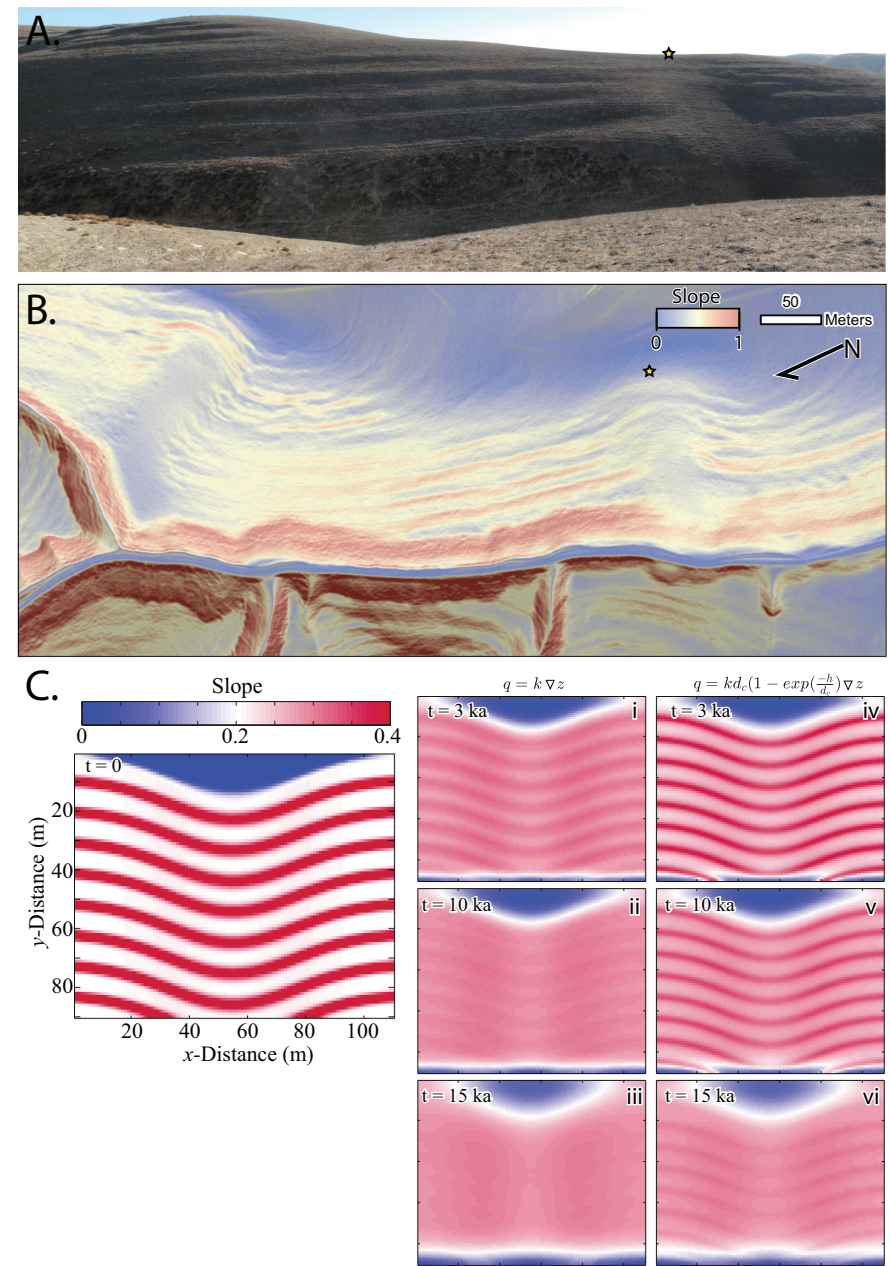

Figure 7: Field observations and simulation results of interactions between colluvial hollows and shadow bedding. A) Photograph of a hillslope highlighting shadow bedding and a colluvial hollow. B) Slope map computed from $1 \mathrm{~m}$ ALSM derived DEM collected and processed by NCALM. C) Results of simulations of evolution of stepped topography. Image at far left shows the slope of initial topography for simulations. Two columns show the evolution of slopes when soil transport is depth-independent (i-iii) and when applying the proposed transport law (iv-vi) with the corresponding flux rules labeled at the top of each column. 